Hydrology and Earth System Sciences, 9, 95-109, 2005

www.copernicus.org/EGU/hess/hess/9/95/

SRef-ID: 1607-7938/hess/2005-9-95

European Geosciences Union

\title{
A conceptual glacio-hydrological model for high mountainous catchments
}

\author{
B. Schaefli, B. Hingray, M. Niggli, and A. Musy \\ Hydrology and Land Improvement Laboratory, Swiss Federal Institute of Technology, Lausanne, Switzerland
}

Received: 29 December 2004 - Published in Hydrology and Earth System Sciences Discussions: 17 January 2005

Revised: 14 April 2005 - Accepted: 14 June 2005 - Published: 5 July 2005

\begin{abstract}
In high mountainous catchments, the spatial precipitation and therefore the overall water balance is generally difficult to estimate. The present paper describes the structure and calibration of a semi-lumped conceptual glaciohydrological model for the joint simulation of daily discharge and annual glacier mass balance that represents a better integrator of the water balance. The model has been developed for climate change impact studies and has therefore a parsimonious structure; it requires three input times series - precipitation, temperature and potential evapotranspiration - and has 7 parameters to calibrate. A multi-signal approach considering daily discharge and - if available - annual glacier mass balance has been developed for the calibration of these parameters. The model has been calibrated for three different catchments in the Swiss Alps having glaciation rates between $37 \%$ and $52 \%$. It simulates well the observed daily discharge, the hydrological regime and some basic glaciological features, such as the annual mass balance.
\end{abstract}

\section{Introduction}

Discharge estimation from highly glacierized catchments has always been a key hydrological issue in the Swiss Alps, especially for the design and management of hydropower plants and for flood risk studies. However, the interest of scientists and civil engineers in this issue drastically decreased after the main period of dam construction in the middle of the last century. Catchments subjected to a glacier regime show a very constant annual hydrological cycle, the start and the end of the melting season varying little from year to year. For hydroelectricity production, the water management therefore rather relies on the long-term experience than on discharge simulations. In the nineties, land managers started asking

Correspondence to: B. Schaefli

(bettina.schaefli@a3.epfl.ch) for hydrological models able to simulate runoff from these snow- and ice melt affected catchments for flood risk studies. In this context, the main interest was focused on rainfall and snowmelt induced processes and on event-based discharge simulation (e.g. Consuegra et al., 1998). Recently, continuous runoff simulation from glacierized catchments has experienced a regain of interest among scientists, hydropower and land managers, in particular in the context of climate change impact studies (Willis and Bonvin, 1995; Singh and Kumar, 1997; Braun et al., 2000).

In high mountainous catchments, discharge simulation is confronted with a major challenge: The available meteorological data is scarce - at high altitudes nearly inexistent and the spatial variability of the meteorological phenomena very strong. A good spatial interpolation of corresponding data series is therefore difficult and the prevailing extreme conditions imply an important measurement uncertainty. The objective of the present study was to develop a hydrological model that can be applied to these data scarce catchments given that discharge data is available for calibration - and that can be used for climate change impact studies (see Schaefli, 2005). This context imposes a set of modelling constraints, the most important being that the model input variables have to be derivable from current GCMs (Global Circulation Models) outputs. This means that the model should be parsimonious in order to reduce the number of meteorological input variables to the strict minimum.

The mentioned difficulties in spatial interpolation of the meteorological time series are not easy to overcome and especially area-average precipitation is an important source of uncertainty for runoff and water balance simulation. In high mountainous catchments, the glaciers represent the most important water storage reservoir and for water balance simulation, any under- or overestimation of the area-average precipitation can be compensated by simulated ice melt. Glacier mass balance estimated over long time periods is thus a good integrator of the overall water balance of the catchment.

(C) 2005 Author(s). This work is licensed under a Creative Commons License. 


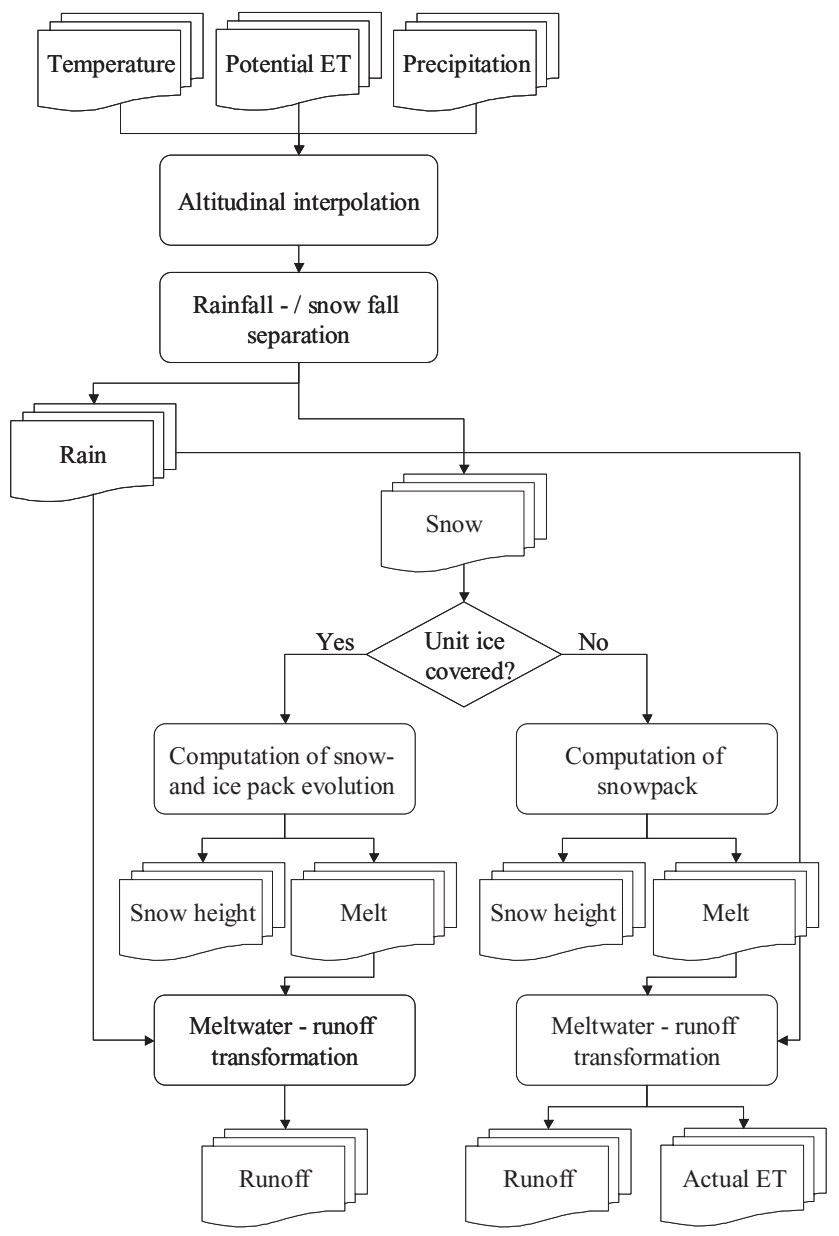

Fig. 1. Hydrological model structure for one spatial unit.

Corresponding observed data can be obtained for glaciers in all ice-covered regions of the world (e.g. Haeberli et al., 2003). Accordingly, the structure of the developed hydrological model has been chosen in order to enable a multisignal calibration based on observed discharge and glacier mass balance data.

This paper presents the hydrological model that has been developed based on the above considerations. The need for a parsimonious structure led us to the development of a conceptual, reservoir-based model having as input variables temperature, precipitation and potential evapotranspiration. The model simulates well the daily discharge, the hydrological cycle and some basic glaciological features as illustrated through the application to three glacierized catchments in the Swiss Alps representing different glaciation rates and hydroclimatic areas. Based on one of these case studies, the calibration of the model and its behaviour is presented in detail. The integration of glacier mass balance data in the calibration process is discussed and corresponding results for the simulation of the mass balance as well as of other glaciological characteristics is illustrated. All these results are directly dependant on the estimated area-average precipitation. Its relationship with the simulated discharge and mass balance is therefore investigated before presenting the main conclusions of this study.

\section{Model description}

The hydrological discharge simulation is carried out at a daily time step through a conceptual, semi-lumped model called GSM-SOCONT (Glacier and SnowMelt - SOil CONTribution model). The catchment is represented as a set of spatial units, each of which is assumed to have a homogenous hydrological behaviour. For each unit, meteorological data series are computed from data observed at neighbouring meteorological stations. Based on these series, snow accumulation and snow- and ice melt are simulated. A reservoir based modelling approach is used to simulate the hydrological response, i.e. the rainfall and melt water - runoff transformation of each unit (Fig. 1). The runoff contributions of all units are added to provide the total discharge at the outlet of the entire catchment. No routing between the spatial units and the river outlet is carried out. In the present modelling context, this simplification is justified by the fact that the studied catchments are relatively small and have rather steep slopes, the runoff delay due to routing in the river network is thus much smaller than the given time step of one day.

In the following, the different modelling steps are described in detail. Additionally, the glacier mass balance computation based on the output of the snow accumulation and snow- and ice melt submodel is presented.

\subsection{Catchment discretization}

The model has two levels of discretization. The first level corresponds to the separation between the ice-covered part of the catchment (covered by glacier or isolated ice patches) and the not ice-covered part. This separation is completed based on available digital land cover data. Each of the two areas is characterized by its surface and its hypsometric curve that is extracted from a digital elevation model. The surface area of the ice-covered part is supposed to be constant throughout a given short-term simulation period (a few years). Even for short simulation periods, this assumption is a rough approximation; the ice-covered area varies throughout the year and from year to year. In extreme years, glacier snouts can retire or advance considerably. In the Swiss Alps more than $100 \mathrm{~m}$ of length change within single years have been observed (e.g. Herren et al., 2001). Such an extreme variation of the snout position concerns however only a small fraction of the total area of a glacier.

The second level of discretization consists in dividing each part of the catchment in a set of elevation bands. Precipitation and temperature time series and the corresponding 
runoff discharge are computed separately for each of the bands. The runoff model depends on whether the band forms part of the ice-covered area or not. For the total catchment, the mean specific runoff $Q(\mathrm{~mm} / \mathrm{d})$ on a given day is therefore:

$$
Q=\frac{1}{a_{c}} \sum_{i=1}^{2} \sum_{j=1}^{n_{i}} a_{i, j} \times Q_{i, j},
$$

where $i$ is an index for each of the two parts of the catchment and $j$ an index for each of the $n_{i}$ elevation bands in part $i$. $a_{i, j}\left(\mathrm{~km}^{2}\right)$ is the area of an elevation band $j$ belonging to the catchment part $i$ and the $Q_{i, j}(\mathrm{~mm} / \mathrm{d})$ the mean daily specific runoff from this spatial unit. $a_{c}\left(\mathrm{~km}^{2}\right)$ is the area of the entire catchment.

\subsection{Meteorological data pre-processing}

The precipitation and temperature time series are interpolated for each elevation band according to its mean elevation. The interpolation is based on an altitude dependent regression of the observations at meteorological measurement stations located in or nearby the study catchments. For the temperature time series, a constant lapse rate is applied to the temperature series measured at the closest meteorological station. This lapse rate is fixed to $-0.65^{\circ} \mathrm{C}$ per $100 \mathrm{~m}$ of altitude increase (the mean gradient of observed temperature series in the studied area). The precipitation increase with altitude is set to a fixed percentage of the amount observed at the used measurement station. For a given catchment, this constant is estimated based on regressions between the mean annual precipitation amounts observed at several precipitation measurement stations located around the catchment.

\subsection{Snow accumulation, snow- and ice melt}

For each elevation band of the catchment, the temporal evolution of the snow pack is computed through an accumulation and a melt model. The aggregation state of precipitation is determined based on a simple temperature threshold:

$$
\begin{aligned}
& P_{\text {snow }}=P_{\text {tot }}, P_{\text {liq }}=0, \quad T \leq T_{0}, \\
& P_{\text {snow }}=0, \quad P_{\text {liq }}=P_{\text {tot }}, T>T_{0},
\end{aligned}
$$

where $P_{\text {tot }}(\mathrm{mm} / \mathrm{d})$ is the total precipitation on a given day, $P_{\text {snow }}(\mathrm{mm} / \mathrm{d})$ the solid and $P_{\text {liq }}(\mathrm{mm} / \mathrm{d})$ the liquid precipitation. $T\left({ }^{\circ} \mathrm{C}\right)$ is the mean daily air temperature and $T_{0}\left({ }^{\circ} \mathrm{C}\right)$ is the threshold temperature.

A correct estimation of the aggregation state of precipitation is essential for the modelling of hydrological processes. The suggested modelling approach (Eq. 2) based on a simple threshold function does however not reflect the observed phenomenon. Observations of the instantaneous form of precipitation (liquid / solid or mixed) suggest the existence of two temperature thresholds, one below which precipitation is almost always solid and a second above which precipitation is almost always liquid. The value of these thresholds depends on the measurement location and can vary throughout the year (Rohrer et al., 1994). Hamdi et al. (2005) have estimated these threshold values for a range of measurement stations located in the present study region and concluded that for most stations they lie between $0^{\circ} \mathrm{C}$ and $2^{\circ} \mathrm{C}$.

These results strongly suggest using a fuzzy transition function for the distribution of precipitation between snowand rainfall (e.g. Klok et al., 2001). We have tested such an approach for the present case studies using the empiric thresholds of $0^{\circ} \mathrm{C}$ and $2^{\circ} \mathrm{C}$ and a linear transition between them. For the given modelling time step of one day and the used spatial discretization (see Sect. 4), this transition interval does not improve the model performance for neither the hydrological nor the mass balance simulation. This result can be explained by the fact that for all three catchments, at most $9 \%$ of the total precipitation occurs on a day and a spatial unit with temperatures in the considered range of $0^{\circ} \mathrm{C}$ and $2^{\circ} \mathrm{C}$. Using a transition interval instead of an abrupt transition at $0^{\circ} \mathrm{C}$ increases the simulated snowfall by a maximum of $6 \%$ for all catchments.

These results indicated that the use of a simple temperature threshold was acceptable for the present study (Eq. 2). For the same reason invoked earlier, its exact value does not significantly influence the model performance but it should ideally also be determined based on instantaneous aggregation state observations. Such observations are not available for all studied catchments. The threshold could also be calibrated together with all other hydrological parameters (see Sect. 4). For the semi-automatic calibration approach proposed in the present paper, we tried however to minimize the number of calibrated parameters. Based on these considerations and for reasons of simplicity, we set the value of the threshold parameter to $0^{\circ} \mathrm{C}$. We would like to emphasize that this choice is justified in the present modelling context but should be reconsidered if the model is applied to different catchments and especially with a different spatial and altitudinal discretization (in particular for coarser resolutions) or for different modelling purposes (e.g. focused on extreme discharge events).

The potential snowmelt $M_{p \text {, snow }}(\mathrm{mm} / \mathrm{d})$ is computed according to a degree-day approach:

$M_{p, \text { snow }}=\left\{\begin{array}{lc}a_{\text {snow }}\left(T-T_{m}\right) & T>T_{m} \\ 0 & T<T_{m}\end{array}\right.$,

where $a_{\text {snow }}$ is the degree-day factor for snowmelt $\left(\mathrm{mm} / \mathrm{d} /{ }^{\circ} \mathrm{C}\right)$ and $T_{m}$ the threshold temperature for melting that is set to $0^{\circ} \mathrm{C}$. The actual snowmelt $M_{\text {snow }}(\mathrm{mm} / \mathrm{d})$ is computed depending on the available snow height $H_{S}$ ( $\mathrm{mm}$ water equivalent).

In the past, comparisons of snowmelt models showed that this simple, empirical approach has an accuracy comparable to more complex energy budget formulations (WMO, 1986). At a small time step, such as a daily time step, it should however only be used in connection with an adequate snowmeltrunoff transformation model (Rango and Martinec, 1995) 
rather than considering the catchment runoff being directly equal to the computed snowmelt.

Recent work shows that the use of the degree-day method is justified more on physical grounds than previously has been assumed (Ohmura, 2001). The incorporation of radiation data into the basic degree-day equation could give better results for snowmelt estimations (see, e.g. Kustas and Rango, 1994; Hock, 2003). However, data scarcity in high mountainous catchments and the need of a parsimonious model structure imposed by the presented modelling context prevented us from applying such a more complex approach.

The transformation of snow (fallen during the last accumulation season) into firn (snow that has not melted during the melting season) or into ice is not modelled. Accordingly, the degree-day factor for snow is used throughout the simulation period for the melting of the snow pack (composed of fresh snow, last winter's snow and firn). In comparable models, several authors use the three different aggregation states (snow, firn and ice) of accumulated water (see, e.g., Baker et al., 1982; Klok et al., 2001). We have shown that for the analysed hydro-climatic area, the use of a separate degreeday factor for firn does not improve neither the discharge nor the mass balance simulation (Schaefli et al., 2004; Schaefli, 2005). Note however that this result is presumably due to the over-parameterisation of the model with respect to the observed data and is probably not confirmed if observed data is available at a higher temporal or spatial resolution.

On the ice-covered spatial units, the same degree-day approach as for snow is used for the ice melt computation, replacing all subscripts snow of Eq. (3) by the subscript ice. Ice melt only occurs on days where the entire snow pack has disappeared $\left(H_{s}=0\right)$. As mentioned before, the ice storage is assumed to be infinite. The snow accumulation and snowand ice melt computation submodel has 2 parameters to calibrate, the degree-day factors for snow $a_{\text {snow }}$ and for ice $a_{\text {ice }}$.

\subsection{Runoff model}

\subsubsection{Ice-covered area}

For the ice-covered catchment part, the runoff model consists of a simple linear reservoir approach inspired by the model presented by (Baker et al., 1982) who proposed to simulate glacier runoff through three parallel different linear reservoirs representing snow, firn and ice. The present model considers only two different aggregation states of accumulated water (see previous section) and accordingly, only two parallel linear reservoirs are used, one for snow and one for ice.

The general linear reservoir equation for the snow reservoir can be written as follows:

$$
\begin{aligned}
& Q_{\text {snow }}\left(t_{i+1}\right)=Q_{\text {snow }}\left(t_{i}\right) \times e^{-\frac{t_{i+1}-t_{i}}{k_{\text {snow }}}} \\
& +\left[P_{\text {liq } \text {, snow }}\left(t_{i+1}\right)+M_{\text {snow }}\left(t_{i+1}\right)\right] \times\left(1-e^{-\frac{t_{i+1}-t_{i}}{k_{\text {snow }}}}\right),
\end{aligned}
$$

where $Q_{\text {snow }}\left(t_{i}\right)(\mathrm{mm} / \mathrm{d})$ is the discharge from the snow reservoir at time step $t_{i}$ and $Q_{\text {snow }}\left(t_{i+1}\right)$ the discharge at the subsequent time step. $k_{\text {snow }}(\mathrm{d})$ is the time constant of the reservoir. $P_{\text {liq, snow }}(\mathrm{mm} / \mathrm{d})$ is the liquid precipitation falling on the snow pack. For the ice reservoir, all subscripts snow of Eq. (4) are replaced by the subscript ice. Note that on a given day $t$, the ice reservoir has no inflow if the spatial unit is snow-covered $\left(P_{\text {liq,ice }}=M_{\text {ice }}=0\right.$ if $\left.H_{s}=0\right)$.

The total runoff from the ice-covered catchment area corresponds to the sum of the ice and snowmelt runoff components. The runoff model for the ice-covered area has 2 parameters to calibrate, namely $k_{\text {ice }}$ and $k_{\text {snow }}$.

\subsubsection{Area not covered by ice}

For each elevation band of this part of the catchment, an equivalent rainfall $P_{\mathrm{eq}}(\mathrm{mm} / \mathrm{d})$ corresponding to the sum of liquid precipitation and snowmelt is computed (Eq. 5).

$P_{\text {eq }}=P_{\text {liq }}+M_{\text {snow }}$,

The equivalent rainfall-runoff transformation in this part of the catchment has to take into account soil infiltration processes and direct runoff. It is carried out through a conceptual reservoir-based model named SOCONT developed by Consuegra and Vez (1996) and similar to the GR-models (Edijatno and Michel, 1989). It is composed of two reservoirs, a linear reservoir for the slow contribution of soil and underground water and a non-linear reservoir for direct runoff. The equivalent rainfall is divided into infiltrated and effective rainfall, supplying water to the slow respectively the direct runoff reservoir.

The slow reservoir has two possible outflows, the base flow $Q_{\text {base }}$ and actual evapotranspiration $E T$. The effective rainfall as well as the actual evapotranspiration is conditioned by the filling rate $S_{\text {slow }} / A$ of the slow reservoir according to the following equations.

$P_{\text {eff }}=P_{\text {tot }} \times\left(S_{\text {slow }} / A\right)^{y}$,

$E T=E T_{0} \times\left(S_{\text {slow }} / A\right)^{x}$,

where $E T(\mathrm{~mm} / \mathrm{d}), E T_{0}(\mathrm{~mm} / \mathrm{d}), P_{\text {eff }}(\mathrm{mm} / \mathrm{d})$ and $P_{\text {tot }}$ $(\mathrm{mm} / \mathrm{d})$ are the actual and potential evapotranspiration, the effective and total rainfall respectively. In the present application, the total rainfall corresponds to the equivalent rainfall. $x$ and $y$ are exponents to be calibrated. $A(\mathrm{~mm})$ is the maximum storage capacity of the reservoir and $S_{\text {slow }}(\mathrm{mm})$ the actual storage. The base flow $Q_{\text {base }}\left(\mathrm{m}^{3} / \mathrm{s}\right)$ is related linearly to the actual storage trough the reservoir coefficient $k_{\text {slow }}$ (Eq. 8)

$Q_{\text {base }}=k_{\text {slow }} \times S_{\text {slow }} \times a_{c}$,

where $a_{c}\left(\mathrm{~m}^{2}\right)$ is the catchment area.

The quick flow component $Q_{\text {quick }}\left(\mathrm{m}^{3} / \mathrm{s}\right)$ is modelled by a non-linear storage-discharge relationship (Eq. 9):

$Q_{\text {quick }}=\beta \times J^{1 / 2} \times H^{5 / 3}$, 
where $J$ is the slope of the catchment, $H(\mathrm{~mm})$ the actual storage and $\beta$ a parameter to calibrate.

The total runoff from the not ice-covered part of the catchment corresponds to the sum of the quick and the base flow. The runoff model for the not ice-covered part has 5 parameters $A, k, x, y$ and $\beta$. According to previous studies (Consuegra and Vez, 1996), the exponent $x$ and $y$ can be set to 0.5 and 2 , respectively. The parameters $A, k$ and $\beta$ have to be calibrated. Several applications of the SOCONT model to non-glacierized catchments (Consuegra et al., 1998; Guex et al., 2002) have shown that this model is able to reproduce all the major characteristics of the discharge such as floods, flow-duration-curves or the hydrological regime.

\subsection{Annual mass balance computation}

The annual mass balance at a given point of a glacier is defined as the sum of water accumulation in form of snow and ice minus the corresponding ablation over the whole year (Paterson, 1994):

$b_{a}=a_{a}+c_{a}=\int_{t_{0}}^{t_{1}}[c(t)+a(t)] d t$,

where $b_{a}(\mathrm{~m})$ is the annual mass balance at a given point, $c_{a}(\mathrm{~m})$ the annual accumulation, $a_{a}(\mathrm{~m})$ the annual ablation, $c(t)(\mathrm{m} / \mathrm{d})$ the accumulation rate at time $t, a(t)(\mathrm{m} / \mathrm{d})$ the ablation rate at time $t, t_{o}$ the start date of the measurement year (here 1 October) and $t_{1}$ the end of the measurement year (30 September the following year). The annual mass balance $B_{a}$ $\left(\mathrm{m}^{3}\right)$ of the entire glacier corresponds to the integration of the point balance over the whole glacier area.

Different methods exist to determine the annual mass balance of a glacier. The data used in the present study has been obtained through the so-called direct glaciological method (Paterson, 1994): The annual mass balance is measured at a representative set of points in the accumulation area and the ablation area. The resulting data are spatially interpolated and superimposed to topographic information in order to obtain the total annual mass balance of the entire glacier.

The presented hydrological model enables the estimation of the annual mass balance based on the hydrological simulation outputs. For each elevation band, the mean annual mass balance is calculated based on the simulated snow accumulation and the simulated snow- and ice melt (Eq. 11).

$b_{a, i}=\int_{t_{0}}^{t_{1}}\left[P_{\text {snow }}(t)-M_{\text {snow }}(t)-M_{\text {ice }}(t)\right] d t$,

where $b_{a, i}(\mathrm{~m})$ is the annual mass balance of the elevation band $i$. The annual mass balance of the entire glacier is estimated as the area-weighted sum of the mass balance of all elevation bands (Eq. 12).

$B_{a}^{\prime}=\frac{1}{s_{g}} \sum_{i=1}^{n}\left(b_{a, i} \times s_{i}\right)$,

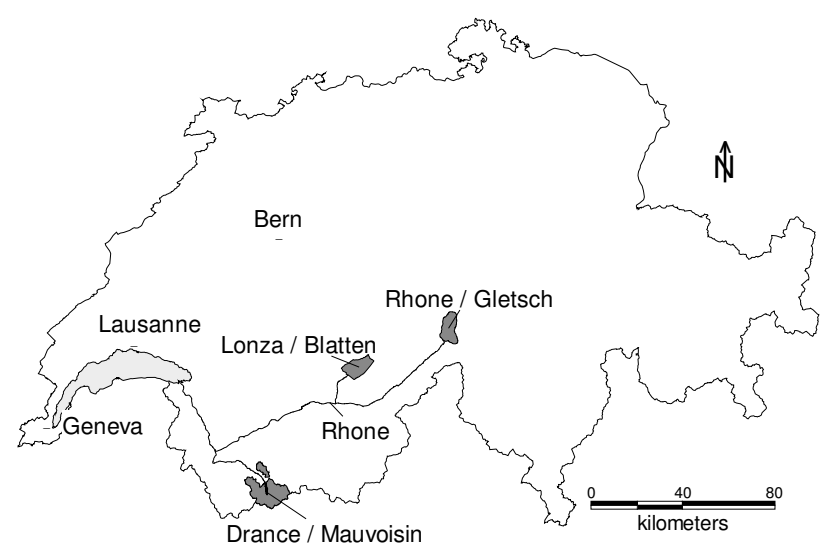

Fig. 2. Location of the case study catchments in the Swiss Alps (SwissTopo, 1997).

where $B_{a}^{\prime}(\mathrm{m})$ is the simulated total annual mass balance of the glacier and $s_{i}\left(\mathrm{~m}^{2}\right)$ is the area of elevation band $i$.

\section{Case studies: site description and data collection}

In the present study, GSM-SOCONT has been applied to three different gauged catchments situated in the Southern Swiss Alps: the Lonza at Blatten, the Rhône at Gletsch and the Drance at the inflow into the dam of Mauvoisin. The hydrological regime of these rivers is strongly influenced by glacier and snowmelt. It is of the so-called a-glacier type (Spreafico et al., 1992): The maximum monthly discharge takes place in July and August and the minimum monthly discharge (up to 100 times less) in February and March.

These three catchments have been chosen because they represent different catchment sizes and have different glaciation ratios (Table 1). Additionally, even though they are all located in the same relatively small geographic area (Fig. 2), the meteorological conditions vary considerably (Table 2).

\subsection{Data collection}

The spatial discretization of the catchment is carried out based on a digital elevation model with a resolution of $25 \mathrm{~m}$ (SwissTopo, 1995) and on digital (vector-based) topographic maps with a scale of 1:25000 (SwissTopo, 1997). The hydrological model needs daily mean values of temperature, precipitation and potential evapotranspiration as meteorological input and daily mean discharge measurements for the model calibration. The precipitation and temperature time series are obtained from the Swiss Meteorological Institute at measurement stations located within a few kilometres distance of the catchments (Table 3). The potential evapotranspiration time series are calculated based on the Penman-Monteith version given by (Burman and Pochop, 1994).

Daily discharge data for the Rhône and the Lonza catchments were provided by the Swiss Federal Office for Water 
Table 1. Main physiographic characteristics of the three catchments (reference year for glaciation: 1985) and the estimated precipitation increase with altitude $\left(c_{\text {precip }}\right)$.

\begin{tabular}{ccccccc}
\hline River & $\begin{array}{c}\text { Area } \\
\left(\mathrm{km}^{2}\right)\end{array}$ & $\begin{array}{c}\text { Glaciation } \\
(\%)\end{array}$ & $\begin{array}{c}\text { Mean altitude } \\
(\mathrm{m} \text { a.s.1. })\end{array}$ & $\begin{array}{c}\text { Altitude range } \\
(\mathrm{m} \text { a.s.l. })\end{array}$ & $\begin{array}{c}\text { Mean slope } \\
\left({ }^{\circ}\right)\end{array}$ & $\begin{array}{c}c_{\text {precip }} \\
(\% / 100 \mathrm{~m})\end{array}$ \\
\hline Rhône & 38.9 & 52.2 & 2713 & $1755-3612$ & 22.9 & 3.1 \\
Lonza & 77.8 & 36.5 & 2601 & $1520-3890$ & 30.0 & 7.9 \\
Drance & 169.3 & 41.4 & 2940 & $1961-4305$ & 26.7 & 2.2 \\
\hline
\end{tabular}

Table 2. Estimated meteorological conditions of the three catchments (reference altitude $2800 \mathrm{~m}$ a.s.1., reference period 1974-1994) and time periods used for the model calibration and validation

\begin{tabular}{cccccc}
\hline River & $\begin{array}{c}\text { Mean annual } \\
\text { precipitation } \\
(\mathrm{mm} / \mathrm{yr})\end{array}$ & $\begin{array}{c}\text { Daily mean } \\
\text { temperature } \\
\left({ }^{\circ} \mathrm{C}\right)\end{array}$ & $\begin{array}{c}\text { Discharge } \\
\text { calibration }\end{array}$ & $\begin{array}{c}\text { Discharge } \\
\text { validation }\end{array}$ & $\begin{array}{c}\text { Mass balance } \\
\text { calibration }\end{array}$ \\
\hline Rhône & 2005 & -5.9 & $1981-1990$ & $1991-1999$ & $1979-1982$ \\
Lonza & 2304 & -3.9 & $1974-1984$ & $1985-1994$ & - \\
Drance & 1449 & -3.2 & $1995-1999$ & $1990-1994$ & - \\
\hline
\end{tabular}

and Geology (see Table 2 for the used time periods). For the Drance catchment, the reference daily discharges are the daily inflows into the accumulation lake of Mauvoisin (used for hydropower production since 1959). These daily inflows are recalculated based on the observed lake level and outflow, both obtained from the Forces Motrices de Mauvoisin. The measurement uncertainty inherent in the inflow estimation is difficult to quantify but it is known to be higher for the validation period than for the calibration period due to a modification of the measurement method. We nevertheless include this catchment in the present study, as the relative uncertainty on observed discharges is not significant during high-flow periods and no undisturbed gauged catchment is available in this particular area of the Swiss Alps.

The calibration procedure for the Rhône catchment uses a second data set, the observed annual mass balance of the Rhône glacier given for the hydrological years 1979/1980 to 1981/1982 by (Funk, 1985). This data set is based on direct glaciological measurements.

\section{Model set-up and calibration}

The model has 7 parameters to calibrate: two degreeday factors $\left(a_{\text {ice }}, a_{\text {snow }}\right)$, three linear reservoir coefficients $\left(k_{\text {slow }}, k_{\text {ice }}, k_{\text {snow }}\right)$, the maximum storage capacity of the slow reservoir $(A)$ and one non-linear reservoir coefficient for the direct runoff $(\beta)$. Note that in the present study, these parameters do not vary in space. The calibration procedure is based on the assumption that during certain periods, some parameters have a much stronger influence on the discharge signal than others and that accordingly, it is possible to define appropriate discriminant calibration criteria.

The overall water balance of the system is conditioned by the timing and intensity of snow- and ice melt, i.e. by the degree-day factors for snow and ice. The slow reservoir parameters $\left(A, k_{\text {slow }}\right)$ are the determinant parameters for reproduction of the base flow during winter months. The reservoir coefficients $k_{\text {snow }}$ and $k_{\text {ice }}$ have a major influence on the simulation quality during summer months, whereas the direct runoff coefficient $\beta$ acts on the model ability to simulate discharge during precipitation events. Based on these considerations, we have developed a multi-signal/multi-objective calibration procedure based on random generation and stepwise local parameter refinement.

The simulation quality is also highly dependent on the used spatial discretization. The number of elevation bands is proportionally distributed between the two types of land cover (ice- and not ice-cover) in accordance to their percentage of the total catchment area. The total number determines the altitudinal resolution of the meteorological time series and of the corresponding simulated snow cover evolution. It has therefore a strong influence on the model performance. It can be shown through simulation, that there is a threshold value beyond which an increase in the number of elevation bands does not result in a model performance increase (Fig. 3). For all 3 catchments, the threshold corresponds to around 10 elevation bands (Fig. 3). The corresponding mean altitudinal intervals vary between 192 m (Rhône catchment) and $242 \mathrm{~m}$ (Drance catchment). Consequently, only 10 elevation bands are used for the simulations presented in this paper. 
Table 3. Meteorological measurement stations used for precipitation $(P)$ and temperature $(T)$ time series and their spatial situation compared to the studied catchments.

\begin{tabular}{cccccc}
\hline River & Station name & $\begin{array}{c}\text { Measured } \\
\text { variable }\end{array}$ & $\begin{array}{c}\text { Station altitude } \\
\text { (m a.s.1.) }\end{array}$ & $\begin{array}{c}\text { Distance to } \\
\text { catchment } \\
\text { centroid }(\mathrm{km})\end{array}$ & $\begin{array}{c}\text { Distance to } \\
\text { nearest, farthest } \\
\text { catchment point }(\mathrm{km})\end{array}$ \\
\hline Rhône & Oberwald & $P$ & 1375 & 8.1 & {$[3.0,14.2]$} \\
Rhône & Ulrichen & $T$ & 1345 & 12.3 & {$[7.4,18.4]$} \\
Lonza & Ried & $P, T$ & 1480 & 6.8 & {$[1.0,13.7]$} \\
Drance & Mauvoisin & $P, T$ & 1841 & 5.1 & {$[0.7,12.7]$} \\
\hline
\end{tabular}

For all simulations, the first two years are assumed to initialise the system and are therefore discarded before the calibration criteria computation. Note that in the following, if nothing else is stated, the numerical examples and illustrations refer to the Rhône catchment.

4.1 Selection of an initial parameter set by random generation

An initial "good" parameter set is chosen among 10000 randomly generated parameter sets. The underlying criteria are the bias between simulated and observed discharge (Eq. 13), the classical Nash criterion (Nash and Sutcliffe, 1970) and a Nash criterion calculated on the log values of the discharges (the Nash-log criterion, Eq. 14).

$V_{\mathrm{e}, \mathrm{d}}=\sum_{t=1}^{n}\left(Q_{\mathrm{obs}, t}-Q_{\mathrm{sim}, t}\right) \times\left(\sum_{t=1}^{n} Q_{\mathrm{obs}, t}\right)^{-1}$,

$R_{\mathrm{eff}, \ln }=1-\sum_{t=1}^{n}\left[\ln \left(Q_{\mathrm{obs}, t}\right)-\ln \left(Q_{\operatorname{sim}, t}\right)\right]^{2}$

$\times\left(\sum_{t=1}^{n}\left[\ln \left(Q_{\mathrm{obs}, t}\right)-\frac{1}{n} \sum_{j=1}^{n} \ln \left(Q_{\mathrm{obs}, j}\right)\right]^{2}\right)^{-1}$,

where $Q_{\mathrm{obs}, t}$ is the observed discharge and $Q_{\text {sim }, t}$ the simulated discharge on day $t$ and $n$ the number of days of the simulation period.

The choice of the initial good parameter set according to these quality criteria is completed based on the following steps: i) Retain all parameter sets with $V_{\mathrm{e}, \mathrm{d}}<0.01$; ii) retain the parameter sets that are among the $1 \%$ best parameters sets for the Nash criteria; iii) retain the parameter sets that are among the $1 \%$ best parameters sets for the Nash-log criteria. If after step i) - iii) more respectively less than one parameter sets are retained, decrease respectively increase the percentage threshold of step ii) and iii).

For the random generation, the parameters are supposed to be uniformly distributed within an interval that can be defined based on some theoretical considerations and on the results of other case studies reported in the literature (Table 4).

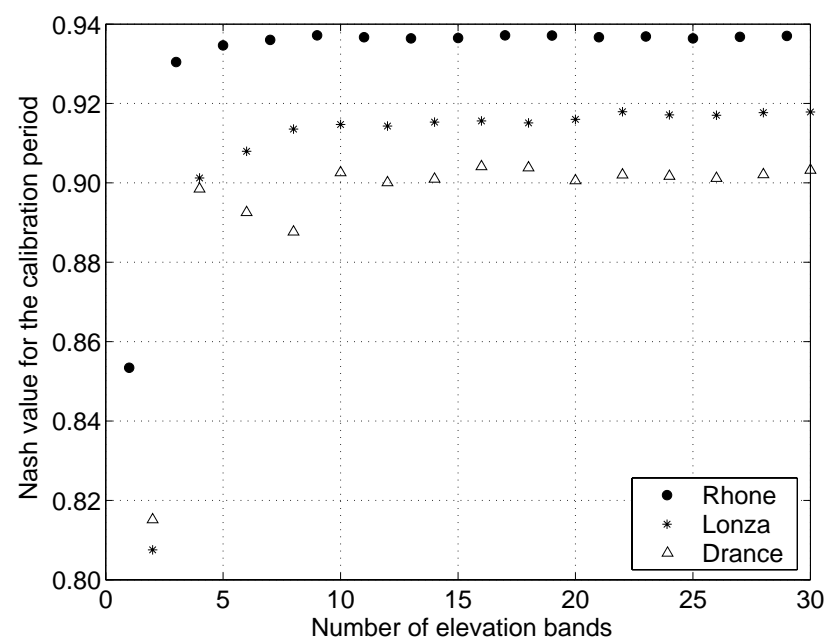

Fig. 3. Model performance (Nash criterion) for the calibration period as a function of the total number of elevation bands (model parameters are fixed to their calibrated values).

Note that the value of the degree-day factor depends on the calculation procedure and especially on the time step chosen (see Braithwaite and Olesen, 1989 for a numerical example). The above ranges must therefore be considered with care. The degree-day factor for ice can be assumed to be higher than for snow because of the higher snow albedo, meaning that the utilization of the available energy is lower for snow than for ice (Braithwaite and Olesen, 1989; Rango and Martinec, 1995). This theoretical consideration has been confirmed by hydro-glaciological studies (Singh et al., 2000).

The random generation within these intervals leads to Nash values higher than 0.9 . For highly glacierized catchments, such high Nash values are easy to achieve as long as the model reproduces the strong seasonality of the discharge. A very simple model corresponding just to the mean observed discharge for each calendar day would yield a Nash value of 0.85 for the calibration period (1981-1990) and a value of 0.81 for the validation period (1991-1999). This means that the classical Nash criterion calculated over the entire calibration period is not sensitive enough for further calibration. 
Table 4. Parameter intervals used for random generation and reference case studies.

\begin{tabular}{ccccl}
\hline Parameter & Unit & Min. value & Max. value & Reference \\
\hline$a_{\text {ice }}$ & $\mathrm{mm} / \mathrm{d} /{ }^{\circ} \mathrm{C}$ & 5.0 & 20.0 & Rango and Martinec, 1995; Singh et al., \\
$a_{\text {snow }}$ & $\mathrm{mm} / \mathrm{d} /{ }^{\circ} \mathrm{C}$ & 1.3 & 11.6 & 2000; Hock,2003 \\
$k_{\text {ice }}$ & $\mathrm{d}$ & 0.2 & 15.0 & Baker et al., 1982; Klok et al., 2001 \\
$k_{\text {snow }}$ & $\mathrm{d}$ & 4.0 & 18.0 & Baker et al., 1982; Klok et al., 2001 \\
$A$ & $\mathrm{~mm}$ & 10 & 3000 & Consuegra et al., 1998; Guex et al., 2002 \\
$\log (k)$ & $\log (1 / \mathrm{h})$ & -12 & -2 & Consuegra et al., 1998; Guex et al., 2002 \\
$\beta$ & $\mathrm{m}^{4 / 3} / \mathrm{s}$ & 100 & 30000 & Consuegra et al., 1998; Guex et al., 2002
\end{tabular}

\subsection{Local refinement}

Based on this first good parameter set, all the parameters are optimised by varying one or two of them and keeping the others constant. For each parameter or couple of parameters an appropriate optimisation criterion is defined. The order of fine-tuning is motivated by the model sensitivity to the 7 model parameters. An initial sensitivity analysis showed that the model performance is the most sensitive to the values of the degree-day factors and the time constant $k$ of the base flow component of the discharge. Accordingly, the degreeday factors are the first parameter couple to optimise. The higher the $a_{\text {ice }}$ value is, the higher is the simulated ice melt contribution to the total runoff. On the other hand, ice melt only occurs when the ice surfaces are not snow-covered (i.e. the bare ice is exposed). The length of these time periods is directly dependent on the $a_{\text {snow }}$ value. The higher it is, the faster the snow cover disappears. It follows that the overall water balance - and consequently the bias between simulated and observed discharge and between simulated and observed annual mass balance of the glaciers - mainly depend on these two parameters. Accordingly, the mean annual discharge bias $\left(V_{\mathrm{e}, \mathrm{d}}\right.$, Eq. 13) is used as an objective function for their fine-tuning. If data is available, the bias between simulated and observed annual mass balance $\left(V_{\mathrm{e}, \mathrm{m}}\right)$ is used as a second objective function (Eq. 15).

$V_{\mathrm{e}, \mathrm{m}}=\frac{1}{n_{y}} \sum_{y=1}^{n_{y}}\left[\operatorname{abs}\left(B_{a, y}-B_{a, y}^{\prime}\right) \times \operatorname{abs}\left(B_{a, y}\right)^{-1}\right]$

where $B_{a, y}(\mathrm{~m})$ is the observed and $B_{a, y}^{\prime}(\mathrm{m})$ the estimated annual mass balance balance of year $y$ and $n_{y}$ the number of simulated years.

For each of these functions, a response surface is generated by varying the two degree-day parameters. For the Rhône catchment, both surfaces show a strong correlation between the two parameters (Fig. 4), the local optima describing a power function of the type $a_{\text {snow }}=\alpha \times a_{\text {ice }}^{\beta}+\gamma$ where $\alpha, \beta$ and $\gamma$ are constants. Hock (1999) found a similar relationship between these two parameters. The curves described by the local optima of both response surfaces have one intersection point. This result has an important implication: By choos- ing this intersection point for the calibrated values of $a_{\text {snow }}$ and $a_{\text {ice, }}$, the model yields good results for the mean annual discharge of the catchment and for the mass balance of the glacier. This ensures that the overall water balance of the system is respected and that the estimated precipitation time series represents well the area-average precipitation. The estimation of this area-average precipitation in high mountainous catchments remains a very difficult task. Aellen and Funk (1990) and Kuhn (2003) pointed out that the total annual snow and ice storage change has about the same order of magnitude as the error committed on area-average precipitation estimation.

We could not find any study in the literature that uses glacier mass balance data for rigorous parameter estimation of a hydrological model for discharge simulation. Such a cross-calibration for river discharge and glacier mass balance has been proposed in the past by Braun and Renner (1992) but for subjective manual calibration of the hydrological model: The mass balance data helped rejecting unrealistic parameter values. Verbunt et al. (2003) used some long-term glacier mass balance aspects for a qualitative model validation.

If no glacier mass balance data is available, the choice of the parameter couple $a_{\text {ice }}$ and $a_{\text {snow }}$ has to be based on an additional calibration criterion for simulated daily discharge. We use the classical Nash criterion that - if computed for all local optima of the bias response surface - has a global optimum.

All other parameters are optimised following a similar approach. For the slow reservoir constants $A$ and $k$, the objective function corresponds to the Nash-log criterion (Eq. 14) as these two parameters have the most important influence on the base flow.

The response surface shows also a strong correlation between the local optima (Fig. 5). This correlation between $A$ and $k$ has already been highlighted in previous studies (Niggli et al., 2001; Guex et al., 2002) for catchments located at much lower elevations. The choice of a parameter couple is not unambiguous, for further calibration, the global optimum is retained. The identified relationship between the two parameters could be useful for further sensitivity analysis. 

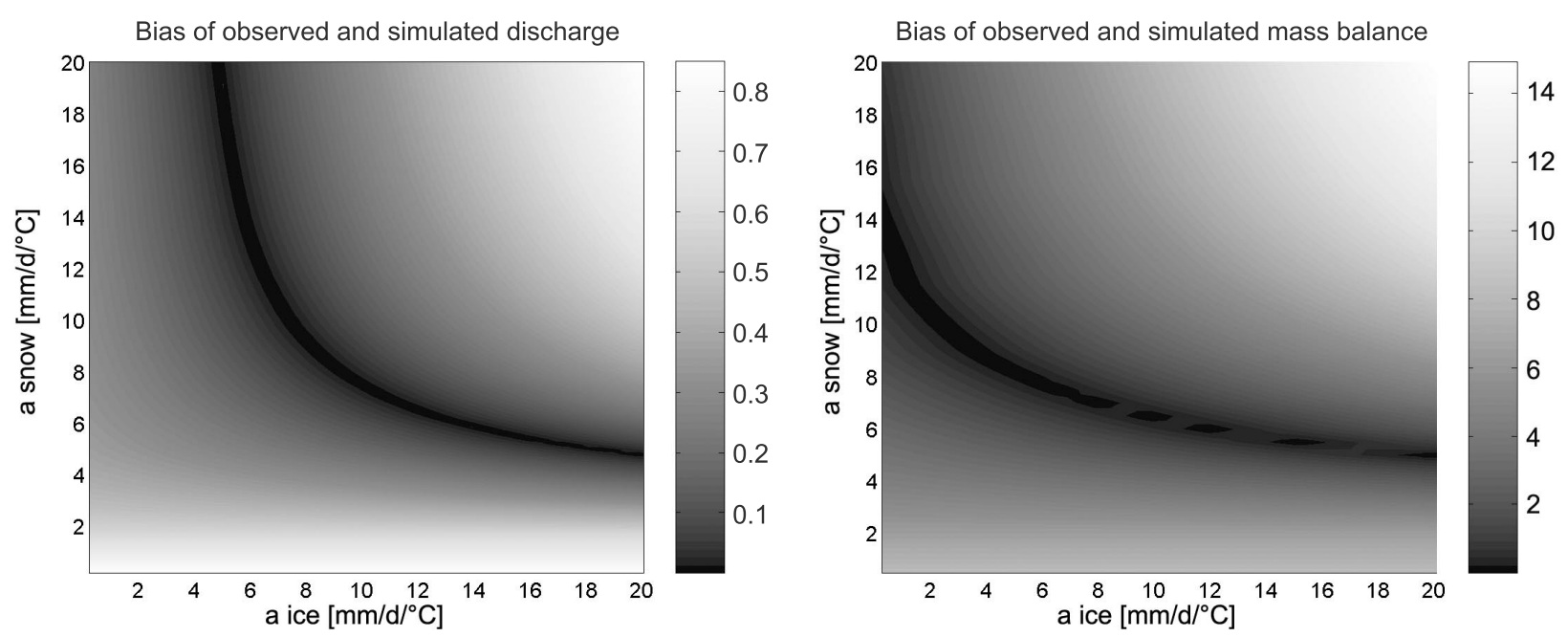

Fig. 4. Response surface of the bias of simulated and observed mean annual discharge (left) and mass balance (right) as a function of snow and ice degree-day factors (Rhône catchment).

The reservoirs coefficients $k_{\text {snow }}$ and $k_{\text {ice }}$ are optimised using the Nash criterion calculated for the period of snowand ice melt (called hereafter Nash-melt criterion). This period has been fixed to the days between i.e. 15 July and 15 September. This objective function has a global optimum. The values of these two parameters can be interpreted as the elapsed time between the moment when melt takes place and the moment when the corresponding water volume reaches the outlet of the catchment. The ice melt water can be assumed to arrive quicker at the outlet, as the internal drainage systems of the glaciers are well developed when ice melt starts taking place. The snowmelt water in contrast can be stored within the snow pack leading to high time intervals between melt and arrival at the outlet.

The remaining model parameter $\beta$ influences the model quality during precipitation events that involve direct runoff in the not ice-covered part of the catchment. These events are generally characterized by a sudden increase of the mean daily discharge. The chosen objective function corresponds therefore to the classical Nash criterion calculated over all days that satisfy the following condition: the ratio between the maximum discharge and the minimum discharge observed during the 3 day period including the preceding, the current and the following day is higher than 1.5 and the total spatial rainfall over the same period is higher than $10 \mathrm{~mm}$. Note that the so identified days can also include runoff events caused by other phenomena than direct runoff. This objective function is called Nash peak and its response curve has a global optimum.

The elaborated parameter optimisation procedure represents a rapid and consistent calibration tool for the glaciohydrological model in use. Its application is subject to the constraint that an initial, good parameter set has been previously identified.

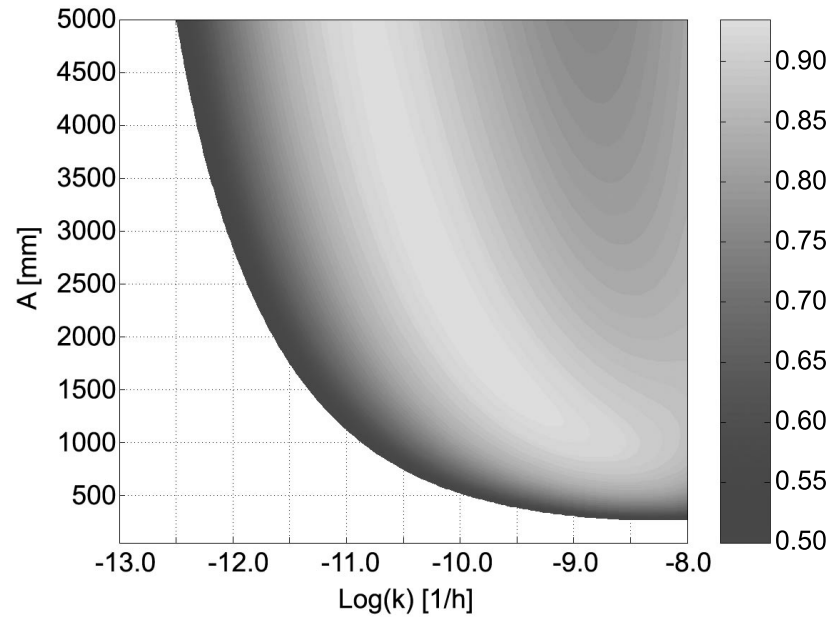

Fig. 5. Variation of Nash-log criterion as a function of $A$ and $\log (k)$; for better readability, values lower than 0.5 are not plotted (Rhône catchment).

\section{Calibration and simulation results}

5.1 Simulation of daily discharge and the hydrological regime

The model has been calibrated and validated for the three catchments Rhône, Lonza and Drance. For the last two, only discharge data was available for calibration. For the model validation, the glaciation rates of the catchments had to be updated (see Table 5). This update is based on available topographic data. For the Drance catchment, no estimate of the ice-cover evolution was available; the used value corresponds to the year 1995 for both periods. 
Table 5. Calibrated parameter values for the 3 catchments and the glaciation rates used for the calibration period (Glac. calib) and the validation period (Glac. valid.).

\begin{tabular}{ccccc}
\hline Parameter & Unit & Rhône & Lonza & Drance \\
\hline$a_{\text {ice }}$ & $\mathrm{mm} / \mathrm{d} /{ }^{\circ} \mathrm{C}$ & 11.5 & 7.1 & 8.0 \\
$a_{\text {snow }}$ & $\mathrm{mm} / \mathrm{d} /{ }^{\circ} \mathrm{C}$ & 6.6 & 6.1 & 4.5 \\
$A$ & $\mathrm{~mm}$ & 2147 & 710 & 1464 \\
$\log (k)$ & $\log (1 / \mathrm{h})$ & -9.9 & -7.4 & -10.8 \\
$k_{\text {ice }}$ & $\mathrm{d}$ & 4.7 & 1.7 & 4.6 \\
$k_{\text {snow }}$ & $\mathrm{d}$ & 5.2 & 4.0 & 5.9 \\
$\beta$ & $\mathrm{m}^{4 / 3} / \mathrm{s}$ & 301 & 2342 & 1213 \\
Glac. calib. & - & 0.52 & 0.38 & 0.41 \\
Glac. valid. & - & 0.50 & 0.36 & 0.41 \\
\hline
\end{tabular}

Table 6. Calibration criteria values (Nash, Nash-log and bias) for the 3 catchments for the calibration and the validation period.

\begin{tabular}{ccccc}
\hline Criterion & Period & Rhône & Lonza & Drance \\
\hline Nash & Calibration & 0.94 & 0.92 & 0.90 \\
Nash & Validation & 0.92 & 0.91 & 0.84 \\
Nash-log & Calibration & 0.93 & 0.88 & 0.83 \\
Nash-log & Validation & 0.93 & 0.93 & 0.79 \\
Bias & Calibration & -0.03 & -0.02 & 0.00 \\
Bias & Validation & -0.00 & 0.03 & 0.05 \\
\hline
\end{tabular}

The calibrated model parameters for all three catchments respect the theoretic considerations stated in Sect. 4, namely $a_{\text {ice }}>a_{\text {snow }}$ and $k_{\text {ice }}<k_{\text {snow }}$ (Table 5). Despite its parsimonious structure, the model shows a good overall performance for the daily discharge simulation over the calibration and the validation periods (Table 6). The model performs particularly well for low flow situations during the winter months (Fig. 6) but also for the periods of snowmelt in late spring and for snow- and ice melt induced high flow situations during the summer months (see the following section for further discussion of high flow simulation). Accordingly, the model reproduces well the observed flow-duration curves (Fig. 6d).

For the Rhône and the Lonza catchment, the model performs equally well for the validation period as for the calibration period (Table 6). This implies in particular that the estimated mean ice-covered areas reflect sufficiently well their contribution to the total runoff during both periods. The Drance catchment however shows an important difference of the model performance for the two simulation periods. Due to the mentioned data quality problems (Sect. 3), this catchment has to be considered separately.

The quality of the observed discharge is considerably lower than for the other two catchments, (especially during low flow situations) and the measurement uncertainty is higher for the validation period than for the calibration pe- riod (for the former 30\% of the observed discharges are negative whereas for the latter only $3 \%$ are negative). During the validation period, the strongest observed negative value is $-2.5 \mathrm{~mm} / \mathrm{d}$, the absolute value of which can be supposed to correspond to the minimum measurement error. We have identified all days showing an observed discharge smaller than this error and set their value equal to the mean observed discharge on all these days. Using this filtered series for simulation performance analysis, the Nash-log value is 0.83 during the validation period (compared to the 0.79 of the initial series). The Nash value is however only slightly improved through the data filtering.

We tested whether the difference of model performance is not simply due to a lack of temporal transposability of the calibrated model. Calibrating the model on the validation period shows that the obtained parameters are very similar to the ones for the initial calibration period $(+/-15 \%)$. The achieved Nash-value is 0.86 , the Nash-log 0.83 and the bias 0.02 . Note however that these parameter values (calibrated for the initial validation period) still yield better results for the initial calibration period (Nash 0.90, unfiltered Nash-log 0.84 , filtered Nash-log 0.87, bias -0.04): Even if the periods are switched, the model performs better for the initial calibration period, a fact that suggests that the lower model performance during the validation period is strongly related to the measurement uncertainty.

In the considered hydro-climatic region, water managers are especially interested in the simulation of high discharge events as they lead regularly to flood situations. The water management implications of these high flow situations depend on the seasonal timing of their appearance. Potentially critical situations can occur during the snow- and ice melt season when the highest annual discharges occur. These high flow events are well simulated by the presented discharge model (Fig. 6). At this time of the year, potential flood situations are generally easily managed especially through the numerous accumulation lakes that have been built for hydropower production all over the Swiss Alps. High discharge events occurring between mid-September and mid-October (Fig. 6b) can induce more critical situations as at this season the accumulation lakes are usually filled up and cannot mitigate the floods. These situations are generally caused by important rainfall events. In high mountainous catchments, such events can be extremely localized and consequently, the simulation of the corresponding discharge is strongly dependant on the representativeness of the precipitation recorded at the measurement station (see, e.g. the high flow event in Fig. 6c, for which no rainfall was recorded). A further discussion of the problem of spatial representativeness of the precipitation follows hereafter. 
(a) Observed and simulated discharge for the Rhone river, year 1987

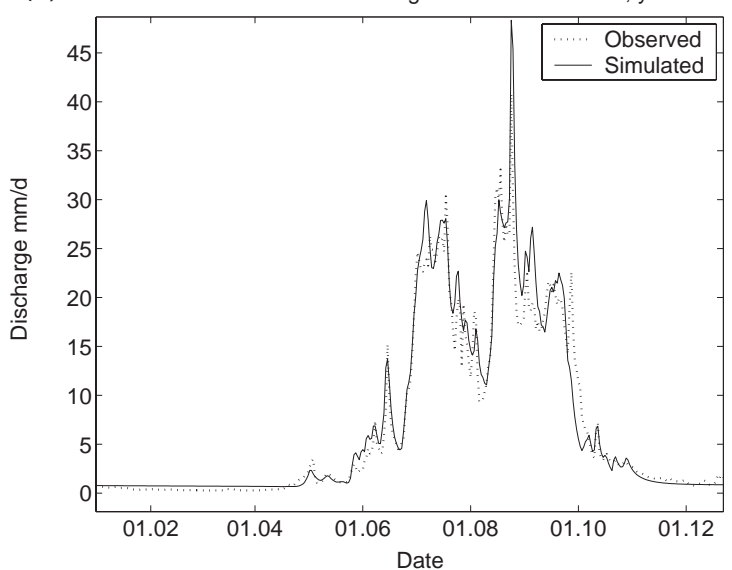

(c)

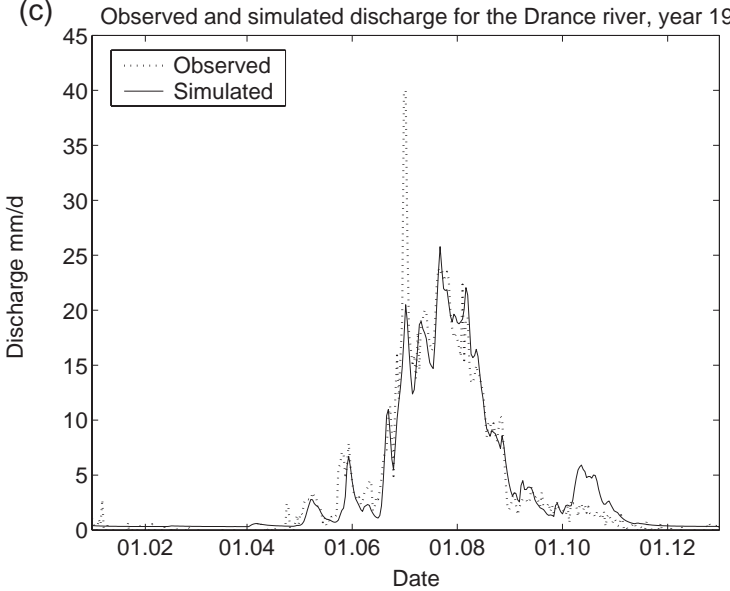

(b) Observed and simulated discharge for the Lonza river, year 1993

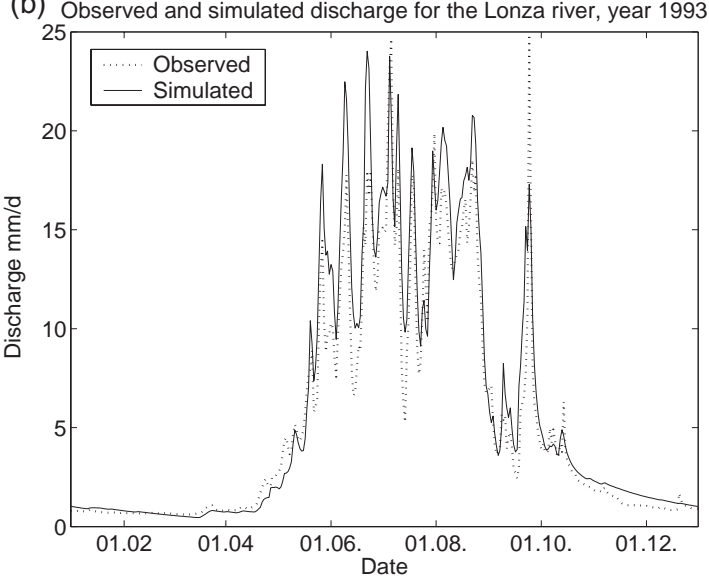

(d) Flowduration curves for the Lonza river, validation period

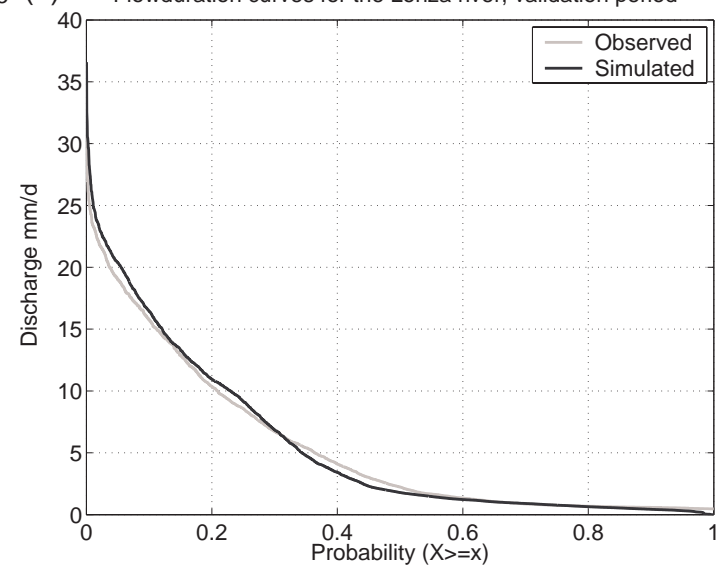

Fig. 6. Observed and simulated discharge: (a) for the Rhône catchment (year 1987); (b) for the Lonza catchment (year 1993); (c) for the Drance catchment (year 1995); (d) observed and simulated flow-duration curves of the Lonza river for the validation period.

Table 7. Simulated and observed total annual mass balance, AAR and ELA.

\begin{tabular}{ccccccc}
\hline \multirow{2}{*}{ Year } & \multicolumn{2}{c}{ Mass balance $(\mathrm{mm} / \mathrm{yr})$} & \multicolumn{2}{c}{ AAR $(\%)$} & \multicolumn{2}{c}{ ELA (m a.s.l.) } \\
& Observed & Simulated & Obs. & Sim. & Obs. & Sim. \\
\hline $1979 / 1980$ & 890 & 835 & 64 & 75 & 2764 & 2682 \\
$1980 / 1981$ & 90 & 115 & 53 & 60 & 2875 & 2831 \\
$1981 / 1982$ & -380 & -1110 & 45 & 36 & 3035 & 3023
\end{tabular}

5.2 Simulation of glacier characteristics for the Rhône glacier

In catchments where glacier mass balance data is available, the GSM-SOCONT can be calibrated on this data. For the Rhône catchment, the mean annual mass balance of the Rhône glacier has been used for the calibration of the degree-day factors. Accordingly, its total annual mass bal- ance is well simulated (Table 7), except for the mass balance year 1981/1982, where it is considerably underestimated (see further discussion hereafter). Note that if the model is calibrated without considering the mass balance data, the retained parameter set would be $a_{\text {ice }}=10.4 \mathrm{~mm} / \mathrm{d} /{ }^{\circ} \mathrm{C}$ and $a_{\text {snow }}=7.2 \mathrm{~mm} / \mathrm{d} /{ }^{\circ} \mathrm{C}$ leading to a less accurate estimate of the annual glacier mass balance (respectively $753 \mathrm{~mm}$, $38 \mathrm{~mm}$ and $-1147 \mathrm{~mm}$ for the period $1979 / 80$ to $1981 / 82$ ).

Beside the total annual mass balance, the reproduction of the observed altitudinal distribution of the mean annual mass balance (Fig. 7) is important for the model performance evaluation. A good reproduction indicates that the processes of snow and ice accumulation and ablation are sufficiently well simulated through the chosen modelling approach considering only precipitation and temperature as underlying driving forces and that the applied spatial interpolation of these driving forces can be assumed to be representative of the real conditions. Note that in some climatic and topographic conditions, snow redistribution by wind and avalanches could also strongly influence the snow accumulation - and conse- 

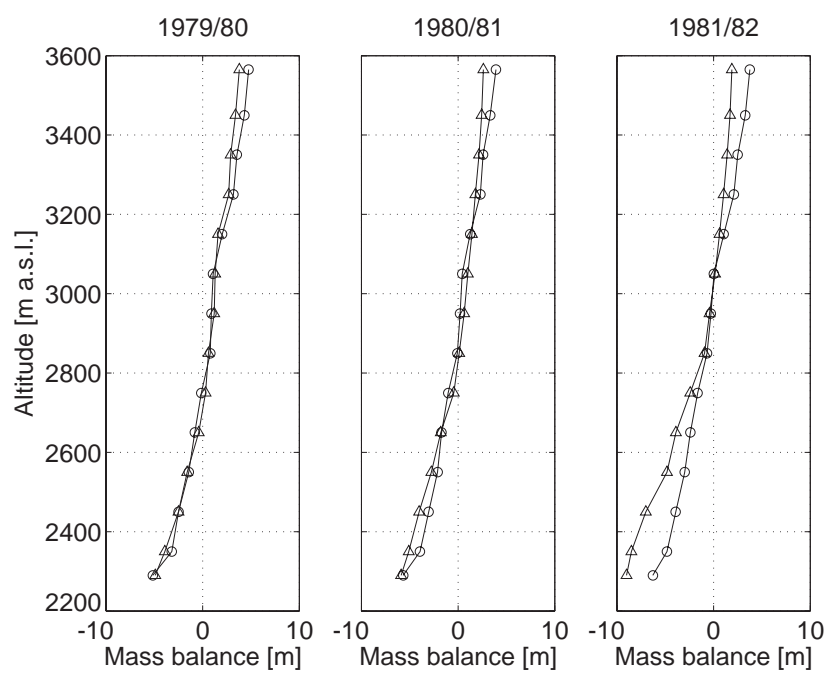

Fig. 7. Observed (circles) and simulated (triangles) mean annual mass balance of the Rhône glacier as a function of altitude for the mass balance years between 1979 and 1982 (the altitudinal discretization and the observed data are drawn from (Funk, 1985)).

quently the mass balance - at a given point (see, e.g., Hartman et al., 1999 and Kuhn, 2003 for an attempt to include this redistribution in a hydrological model).

The presented model reproduces generally well the altitudinal mass balance distribution (Fig. 7) but is not able to reproduce correctly the observed high accumulation in the uppermost parts of the glacier, especially for the mass balance year 1981/82 (Fig. 7). Further research into the exact altitudinal distribution of precipitation could help solving this problem.

The accumulation underestimation in the highest glacier area partly explains the mass balance underestimation during the year 1981/82. In this mass balance year, only the highest spatial units experience a positive net balance and for these units the accumulation is underestimated (Fig. 7). The most important part of the mass balance underestimation is however due to a considerable overestimation of the ablation increase with altitude decrease in the ablation area of the glacier. The mean value obtained based on the glaciological measurements of Funk (1985) is $91 \mathrm{~cm}$ of ablation increase per $100 \mathrm{~m}$ of altitude decrease, whereas the mean simulated value is $111 \mathrm{~cm}$ per $100 \mathrm{~m}$. This results in an ablation simulation of up to $-9 \mathrm{~m}$. This unrealistic value results from the model assumption that the available stock of ice in a given point is infinite whereas in reality the ice in the considered part would disappear. This problem however only concerns the lowest catchment parts, i.e. at most $1 \%$ of the glacier area and cannot explain the general mass balance underestimation. Further research into the particular ablation conditions of this mass balance year would be necessary to determine the cause of the general ablation overestimation.

Two other important descriptors are usually used to characterize a glacier: the equilibrium line altitude (ELA) and

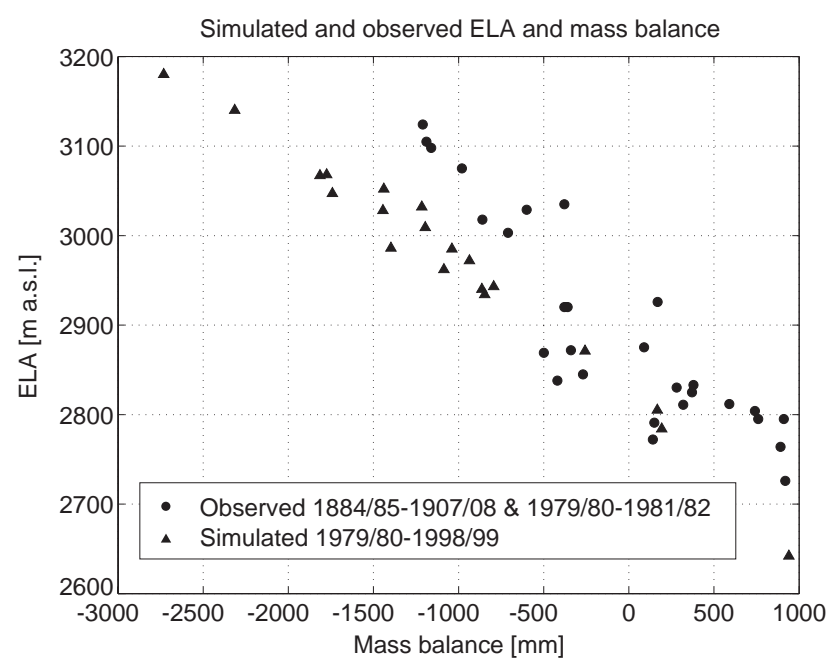

Fig. 8. ELA versus annual mass balance: observed values for 1884/1885-1907/1908 and 1979/1980-1981/1982 (Chen and Funk, 1990) and simulated values for 1979/1980-1998/1999 (Rhône catchment).

the accumulation area ratio (AAR). The ELA is the line connecting all points with zero balance at the end of a fixed year (Anonymous, 1969). It separates the ablation area from the accumulation area. The AAR is the ratio between the accumulation area and the entire glacier area. According to Ohmura et al. (1992), the equilibrium line represents the lowest boundary of the climatic glacierization, i.e. the climatic conditions which prevail at the glacier equilibrium line are considered to be just sufficient to maintain the existence of ice. Ohmura et al. (1992) also point out that knowledge about the ELA is essential for understanding the relationship between climatic changes and glacier variations. The correct simulation of the ELA (respectively the AAR values) is therefore a major objective for the present hydrological model that has been developed for an application in climate change impact studies. The observed ELA and AAR values are well reproduced by the hydrological model (Table 7). For the mass balance year 1981/1982 - even though the total annual mass balance is considerably underestimated - the ELA is very well simulated. The model also reproduces the typical linear relationship between the ELA and the total annual mass balance (Fig. 8) that is characteristic for a given glacier (Aellen and Funk, 1990; Kulkarni, 1992; Herren et al., 2002). The simulated slope is close to the one observed in the past.

This model feature enables its use for a glacier surface evolution model based on the AAR concept. This concept is classically used to reconstruct paleoclimatic glacier surfaces (see, e.g. Porter, 1975; Torsnes et al., 1993). As shown by Schaefli (2005), it can be used - in an extended form - for the prediction of the glacier surface for future climate conditions. 

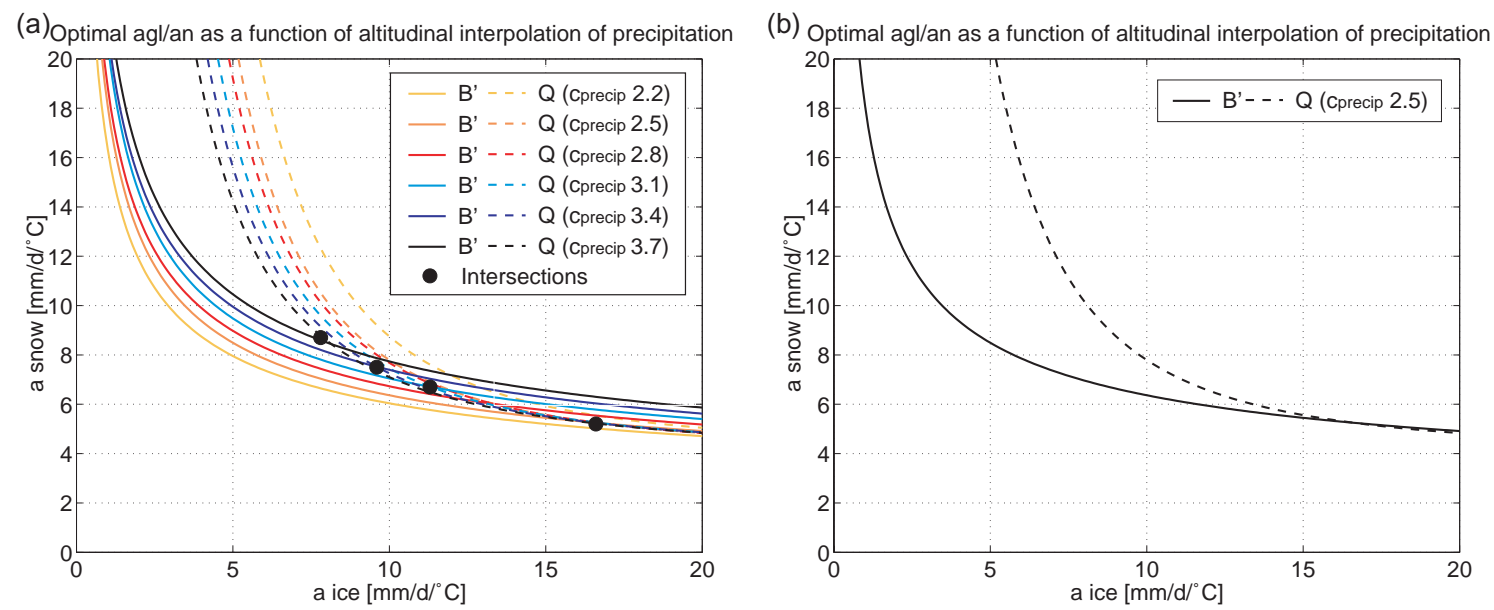

Fig. 9. Optimal curves of mass balance and discharge bias as a function of $a_{\text {icee }}, a_{\text {snow }}$ and $c_{\text {precip }}$ (Rhône catchment); values of $c_{\text {precip }}$ in brackets (unit: \%/100 m).

A consequent modelling approach would ask for a validation of the obtained mass balance simulations for another period. Long series of mass balance observations are however difficult to obtain. It is noteworthy that many published series of mass balance data are in fact the result of a hydrological water balance estimation (see, e.g. Spreafico et al., 1992). Accordingly, they do not encode an additional source of information as they are directly related to the discharge measurement.

\subsection{Simulation results and area-average precipitation}

As mentioned earlier in this paper, the estimation of areaaverage precipitation for high mountainous catchments is a considerable source of modelling uncertainty. Due to the high spatial variability of precipitation in such catchments, two main problems arise: i) the precipitation events recorded at the measurement station(s) are not necessarily representative for the events effectively occurred in the catchment and ii) the amount of precipitation at a given catchment point based on the precipitation records is difficult to estimate.

In the present modelling context, the first problem can be assumed to have an important influence on the daily discharge simulation for rainfall-induced high-flow events. A detailed analysis would require more spatially distributed precipitation data (e.g. based on radar measurements) and is therefore beyond the study context. The second problem is taken into account by the interpolation of the precipitation for each elevation band based on a constant altitudinal increase ( $c_{\text {precip }}$ ) of the precipitation observed at the measurement station. In high mountainous areas, the value of $c_{\text {precip }}$ is highly difficult to estimate and it could even be justifiable to calibrate this parameter as it is frequently done in hydroglaciological studies (e.g. Kuhn, 2000). Its calibration based on discharge and glacier mass balance data would however clearly suffer from over-parameterisation, as the two degree- day factors and $c_{\text {precip }}$ are mutually interdependent. The curve of optimal values of $a_{\text {ice }}$ and $a_{\text {snow }}$ in terms of discharge or mass balance bias undergoes a shift when varying $c_{\text {precip }}$ (Fig. 9a). This shift is in the opposite direction for the discharge bias than for the mass balance bias and consequently the intersection points between these two curves also describe a power function (Fig. 9a). If $c_{\text {precip }}$ is higher than $3.6 \% / 100 \mathrm{~m}$, the value of $a_{\text {ice }}$ of the intersection point is lower than the value of $a_{\text {snow }}$. Such couples of degreeday factors are contrary to the basic theoretic considerations stated in Sect. 4. The smaller $c_{\text {precip }}$ is, the closer are the two curves at their right-hand tails and the less well defined is the best parameter couple $a_{\text {ice }} / a_{\text {snow }}$ (Fig. 9b). For small values of $c_{\text {precip }}$ the intersection point corresponds to unreasonable

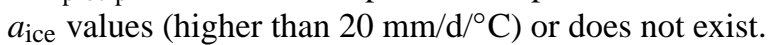

This leads to the conclusion that it is not possible to fix a unique best value for $c_{\text {precip. The multiresponse calibration }}$ through the joint use of discharge and glacier mass balance data enables however the definition of an interval of possible values for $c_{\text {precip }}$ that for the Rhône catchment corresponds to $[2.3 \% / 100 \mathrm{~m}, 3.8 \% / 100 \mathrm{~m}]$. A detailed analysis of the influence of $c_{\text {precip }}$ on the model ability to simulate the presented glaciological characteristics (AAR, ELA and altitudinal mass balance distribution) could possibly lead to some further conclusions.

\section{Conclusions}

The presented hydrological model is based on a simple reservoir approach that includes the basic glacio-hydrological features, namely soil infiltration and melt water storage in the snow cover and the glacier. The model gives good results for mean daily discharge simulation from highly glacierized catchments as illustrated through its application to three catchments in the Swiss Alps. It simulates well the hydrological regime and reproduces some basic glaciological features 
such as the total annual glacier mass balance or the accumulation area ratio. This characteristic makes the model particularly interesting for applications in climate change impact studies as the simulation results can be used for glacier surface evolution studies (Schaefli et al., 2005 ${ }^{1}$; Schaefli, 2005). The parsimonious model structure is also adapted to such applications: All required climatic input variables can be obtained from current climate models. Given the simplicity of the model structure and its effectiveness for discharge and mass balance simulations, the model represents also an easy to use simulation tool to study highly glacierized alpine catchments in other contexts, such as water resources management.

The elaborated procedure of parameter calibration represents a rapid and consistent calibration tool for the model. The presented multi-signal calibration of the river discharge and the glacier mass balance constitutes an interesting approach for the estimation of the total water balance of highly glacierized catchments. In mountainous areas, the spatial distribution of precipitation represents an important source of uncertainty. Calibrated rainfall-runoff models can give good estimates of the discharge even if the spatial precipitation is estimated poorly. Differences between simulated and real precipitation can typically be compensated by simulated evapotranspiration or as in the present model by simulated ice melt. This does not represent a real problem for applications where the main interest lies in short-term prediction of the daily discharge. In long-term projections however, a wrong overall water balance simulation can be significantly misleading, especially in the present context where the ice melt contribution to the runoff could be completely under- or overestimated.

The model does not account for seasonal variations of the physical system even if the subglacial drainage system is known to undergo a strong evolution throughout the melt season. The drainage network as well as the channel sizes vary in response to changing water inputs (Röthlisberger, 1972; Hubbard and Nienow, 1997). This evolution of the internal drainage system can be assumed to have a notable influence on the discharge. In order to improve the discharge simulations, further investigation in the time-dependency of the parameters could be interesting, considering especially potential links between the parameters and climate variables.

It should be kept in mind that the proposed parameter calibration approach - random search completed by local refinement - guarantees neither that the globally best parameter set nor that all possibly good parameter sets are found. A quantitative parameter and model uncertainty analysis such as the one presented by Kuczera and Parent (1998) would

\footnotetext{
${ }^{1}$ Schaefli, B., Hingray, B. and Musy, A.: Climate change and hydropower production in the Swiss Alps: Quantification of potential impacts and related modelling uncertainties, Hydrol. Earth Sys. Sci., submitted, 2005
}

complete the current results (Schaefli et al., 2005²). Such an uncertainty analysis could in particular make use of the identified relationships between some of the model parameters and produce confidence intervals on the simulated daily discharge and annual glacier mass balance.

Acknowledgements. We wish to thank the Forces Motrices de Mauvoisin and the Swiss Federal Office for Water and Geology for providing the discharge data and the national weather service MeteoSwiss for providing the meteorological time series. The model was developed in the context of the European project SWURVE (Sustainable Water: Uncertainty, Risk and Vulnerability in Europe, funded under the EU Environment and Sustainable Development programme, grant number EVK1-2000-00075) that analyses climate change impacts on water resources systems in Europe. The Swiss part of this project was funded by the Federal Office for Education and Science, contract number 00.0117.

Edited by: J. Seibert

\section{References}

Aellen, M. and Funk, M.: Bilan hydrologique du bassin versant de la Massa et bilan de masse des glaciers d'Aletsch (Alpes Bernoises, Suisse), in: Hydrology in Mountainous Regions I: Hydrological Measurements; the Water Cycle, edited by: Lang, H. and Musy, A., IAHS Publ. No. 193, Wallingford, Oxfordshire UK, 89-98, 1990.

Anonymous: Mass-balance terms, J. Glaciol., 8, 3-7, 1969.

Baker, D., Escher-Vetter, H., Moser, H., Oerter, H., and Reinwarth, O.: A glacier discharge model based on results from field studies of energy balance, water storage and flow, in: Hydrological Aspects of Alpine and High-Mountain Areas, edited by: Glenn, J. W., IAHS Publ. no. 138, Wallingford, Oxfordshire UK, 103-112, 1982.

Braithwaite, R. J. and Olesen, O. B.: Calculation of glacier ablation from air temperature, West Greenland, in: Glacier fluctuations and climatic change, edited by: Oerlemans, J., Proceedings of the Symposium on Glacier Fluctuations and Climatic Change, held in Amsterdam, 1-5 June 1987, Glaciology and quaternary geology, Kluwer Academic Publishers, Dordrecht, 219-233, 1989.

Braun, L. N. and Renner, C. B.: Application of a conceptual runoff model in different physiographic regions of Switzerland, Hydrolog. Sci. J., 37, 217-231, 1992.

Braun, L. N., Weber, M., and Schulz, M.: Consequences of climate change for runoff from Alpine regions, Ann. Glaciol., 31, 19-25, 2000.

Burman, R. and Pochop, L. O.: Evaporation, evapotranspiration and climatic data, Elsevier, Amsterdam, 278 pp, 1994.

Chen, J. and Funk, M.: Mass balance of Rhônegletscher during 1882/1983-1986/1987, J. Glaciol., 36, 199-209, 1990.

Consuegra, D., Niggli, M., and Musy, A.: Concepts méthodologiques pour le calcul des crues, application au bassin versant supérieur du Rhône, Eau, énergie, air, 9/10, 223-231, 1998.

\footnotetext{
${ }^{2}$ Schaefli, B., Talamba, D., and Musy, A.: Quantifying hydrological modelling errors through finite mixture distributions, J. Hydrol., submitted, 2005
} 
Consuegra, D. and Vez, E.: AMIE - Analyse et Modélisation Intégrées du cheminement des Eaux en zones habitées, modélisation hydrologique, Application au bassin versant de la Haute Broye, IATE/HYDRAM, Swiss Institute of Technology, Lausanne, Lausanne, 1996.

Edijatno and Michel, C.: Un modèle pluie-débit journalier à trois paramètres, La Houille Blanche, 2, 113-121, 1989.

Funk, M.: Räumliche Verteilung der Massenbilanz auf dem Rhônegletscher und ihre Beziehung zu Klimaelementen, Doctoral Thesis, Eidgenössische Technische Hochschule Zürich, 183 pp, 1985.

Guex, D., Guex, F., Pugin, S., Hingray, B., and Musy, A.: Regionalisation of hydrological processes in view of improving model transposability. WP3 Final Report of the Pan-European FRHYMAP Project (Flood Risk scenarios and Hydrological MAPping), No. Contract CE: 3/NL/1/164/99 15183 01., Swiss Institute of Technology, Lausanne, Lausanne, 2002.

Haeberli, W., Frauenfelder, R., and Hoelzle, M. (eds.): Glacier mass balance bulletin no. 7 (2000-2001). IAHS - UNEP - UNESCO - WMO, Zürich, Switzerland, 87 pp, 2003.

Hamdi, Y., Hingray, B., and Musy, A.: Un modèle de prévision hydro-météorologique pour les crues du Rhône supérieur en Suisse, Conférence sur la recherche appliquée en relation avec la IIIİme correction du Rhône, Martigny, Switzerland, 2005.

Hartman, M. D., Baron, J. S., Lammers, R. B., Cline, D. W., Band, L. E., Liston, G. E., and Tague, C.: Simulations of snow distribution and hydrology in a mountain basin, Water Resour. Res., 35, 1587-1603, 1999.

Herren, E. R., Bauder, A., Hoelzle, M., and Maisch, M.: The Swiss Glaciers 1999/2000 and 2001/2002. 121/122, Glaciological Commission of the Swiss Academy of Sciences, Zürich, 2002.

Herren, E. R., Hoelzle, M., and Maisch, M.: The Swiss Glaciers 1997/1998 and 1998/1999. 119/120, Glaciological Commission of the Swiss Academy of Sciences, Zürich, 2001.

Hock, R.: A distributed temperature-index ice- and snowmelt model including potential direct solar radiation, J. Glaciol., 45, 101$111,1999$.

Hock, R.: Temperature index melt modelling in mountain areas, J. Hydrol., 282, 104-115, 2003.

Hubbard, B. and Nienow, P.: Alpine subglacial hydrology, Quat. Sci. Rev., 16, 939-955, 1997.

Klok, E. J., Jasper, K., Roelofsma, K. P., Gurtz, J., and Badoux, A.: Distributed hydrological modelling of a heavily glaciated Alpine river basin, Hydrolog. Sci. J., 46, 553-570, 2001.

Kuczera, G. and Parent, E.: Monte Carlo assessment of parameter uncertainty in conceptual catchment models: the Metropolis algorithm, J. Hydrol., 211, 69-85, 1998.

Kuhn, M.: Verification of a hydrometeorological model fo glacierized basins, Ann. Glaciol., 31, 15-18, 2000.

Kuhn, M.: Redistribution of snow and glacier mass balance from a hydrometeorological model, J. Hydrol., 282, 95-103, 2003.

Kulkarni, A. V.: Mass balance of Himalayan glaciers using AAR and ELA methods, J. Glaciol., 38, 101-104, 1992.

Kustas, W. P. and Rango, A.: A simple energy budget algorithm for the snowmelt runoff model, Water Resour. Res., 30, 1515-1527, 1994.

Nash, J. E. and Sutcliffe, J. V.: River flow forecasting through conceptual models, Part I, a discussion of principles, J. Hydrol., 10,
282-290, 1970.

Niggli, M., Hingray, B., and Musy, A.: A Methodology for Producing Runoff Maps and Assessing the Influence of Climat Change in Europe in WRINCLE (Water Resources: Influence of Climate Change in Europe), Swiss Federal Institute of Technology Lausanne, Lausanne, 2001.

Ohmura, A.: Physical basis for the temperature-based melt-index method, J. Appl. Meteorol., 40, 753-761, 2001.

Ohmura, A., Kasser, P., and Funk, M.: Climate at the equilibrium line of glaciers, J. Glaciol., 38, 397-411, 1992.

Paterson, W. S. B.: The Physics of Glaciers, Pergamon, Oxford, 480 pp, 1994.

Porter, S. C.: Equilibrium-line altitudes of late quaternary glaciers in southern alps, New Zealand, Quat. Res., 5, 27-47, 1975.

Rango, A. and Martinec, J.: Revisiting the degree-day method for snowmelt computations, Water Resour. Bull., 31, 657-669, 1995.

Rohrer, M. B., Braun, L. N. and Lang, H.: Long-term records of snow cover water equivalent in the Swiss Alps. 2. Simulations, Nord. Hydrol., 25(1-2), 65-78, 1994.

Röthlisberger, H.: Water pressure in intra- and subglacial channels, J. Glaciol., 11, 177-203, 1972.

Schaefli, B.: Quantification of modelling uncertainties in climate change impact studies on water resources : Application to a glacier-fed hydropower production system in the Swiss Alps. Doctoral thesis, Ecole Polytechnique Fédérale de Lausanne, 204 pp, 2005.

Schaefli, B., Hingray, B., and Musy, A.: Improved calibration of hydrological models: use of a multi-objective evolutionary algorithm for parameter and model structure uncertainty estimation, in: Hydrology: Science and Practice for the 21st Century, edited by: Webb, B., British Hydrological Society, London, pp. 362371, 2004.

Singh, P. and Kumar, N.: Impact assessment of climate change on the hydrological response of a snow and glacier melt runoff dominated Himalayan river, J. Hydrol., 193, 316-350, 1997.

Singh, P., Kumar, N., and Arora, M.: Degree-day factors for snow and ice for Dakriani Glacier, Garhwal Himalayas, J. Hydrol., 235, 1-11, 2000.

Spreafico, M., Weingartner, R., and Leibundgut, C.: Atlas hydrologique de la Suisse, Service Hydrologique et Géologique National (SHGN), Bern, 1992.

Swiss Topo: Digital height model of Switzerland - DHM25, Waber, Switzerland, 1995.

Swiss Topo: Digital National Maps of Switzerland - PM25, Waber, Switzerland, 1997.

Torsnes, I., Rye, N., and Nesje, A.: Modern and little iceage equilibrium-line altitudes on outlet valley glaciers from Jostedalsbreen, Western Norway - an evaluation of different approaches to their calculation, Arct. Alp. Res., 25, 106-116, 1993.

Verbunt, M., Gurtz, J., Jasper, K., Lang, H., Warmerdam, P., and Zappa, M.: The hydrological role of snow and glaciers in alpine river basins and their distributed modeling, J. Hydrol., 282, 3655, 2003.

Willis, I. and Bonvin, J.-M.: Climate change in mountain environments: hydrological and water resource implications, Geography, 80, 247-261, 1995.

WMO: Intercomparison of models of snowmelt runoff, WMO, Geneva, 1986. 